\title{
Announcement
}

\section{EUSIDIC Spring Meeting}

\section{1-12 March 2002, Université Marne la Vallée, Paris, France}

e-Content: Divide or Rule

EUSIDIC will organise a two day program of presentations and informal discussion opportunities in Paris next Spring. The theme of the meeting will be Content Management:

- status and current developments

- business models, including pricing models

- case studies

- the integration of web-based content

- content syndication and aggregation

- legal aspects and copyright developments (including the latest EU Directive)

EUSIDIC aims for highly participative discussions with delegates and presenters, in a workshop style. There will be a maximum of 6 papers presented in order to stimulate discussion.

If you have an interesting case study or a provocative view on these topics, the Organising Committee would like to hear from you. Please send the EUSIDIC Secretariat a short summary of about 200 words by 15 November 2001 .

Organising Committee: Johan van Halm, Daphne Tomlinson, Christa Brûlet, Dominique Vanpée, Frank Spellerberg, Irja Laamanen.

EUSIDIC Secretariat: c/o FIZ Karlsruhe, 76344 Eggenstein - Leopoldshafen, Germany. Tel: +49 7247 808 403; Fax: +49 7247808 114; E-mail: eusidic@ fiz-karlsruhe.de; URL: http://www.eusidic.org. 